\title{
The connection between maternal thiamine shortcoming and offspring cognitive damage and poverty perpetuation in underprivileged communities across the world
}

\author{
Fernando M.V. Dias ${ }^{\mathrm{a}, \mathrm{b}, *}$, Danielle Marra de Freitas Silva ${ }^{\mathrm{c}}$, Flavia Costa de Proença Doyle ${ }^{\mathrm{b}}$, \\ Angela Maria Ribeiro ${ }^{c}$ \\ a Department of Medicine and Nursing, Federal University of Viçosa, Viçosa, Brazil \\ ${ }^{\mathrm{b}}$ Graduate Program in Neurosciences, Laboratory of Molecular and Behavioral Neuroscience, LaNeC, Federal University of Minas Gerais, Belo Horizonte, Brazil \\ ${ }^{\mathrm{c}}$ Biochemistry and Immunology Department, Laboratory of Molecular and Behavioral Neuroscience, LaNeC, Federal University of Minas Gerais, Belo Horizonte, Brazil
}

\section{A R T I C L E I N F O}

\section{Article history:}

Received 29 May 2012

Accepted 20 September 2012

\begin{abstract}
A B S T R A C T
The acquisition of cognitive, sensory-motor and social emotional functions depend on a proper development of the Central Nervous System (CNS). This set of functions, known as intelligence, allows a better adaptation to the environment. In the last decades, an increase in the average of intelligence has been reported. However, such an increase cannot be observed in an equivalent way in economically and social underprivileged regions. Children from those regions are in great risk of being affected by mental retardation or impaired cognitive development. In later life they will, probably, be unable to transform and improve themselves and their communities, perpetuating the poverty of the region. Therefore, knowledge of factors involved in CNS development is a matter of health closely related to social improvement.

Malnutrition throughout pregnancy and breastfeeding is clearly identifiable as a cause of damage in CNS development. Vitamin B1 (Thiamine) is a micronutrient important to the growth and maturity of the CNS. Thiamine shortcoming may affect $50 \%$ of pregnant women. Thiamine function in cerebral development is still not well known. There is a gap in the literature regarding systematical research about the blood thiamine concentration throughout the periods of gestation and breastfeeding. These studies are relevant in populations with a high level of nutritional vulnerability, because in a follow up offspring cognitive exam they could reveal if the maternal thiamine deficiency is related to child CNS impairment.

This paper introduce the hypothesis that thiamine shortcoming during pregnancy and breastfeeding is directly related to cognitive impairment of child. Data about the neurophysiological role of thiamine, consequences of its shortcoming in experimental models, populations under the risk of thiamine shortcoming are presented.

The hypothesis that maternal thiamine shortcoming causes damage related to child cognitive development needs to be considered. Thus, thiamine shortcoming during gestation and breastfeeding and its effects on children must be studied in many populations in order to know the magnitude of the problem and to indicate actions to overcome it.
\end{abstract}

(c) 2012 Published by Elsevier Ltd.

\section{Introduction}

Throughout human development, according to the growth and maturity of the central nervous system (CNS), new abilities that allow a better adaptation to the environment are incorporated. The set of cognitive functions, sensory-motor, social emotion that allow interaction with the environment is known as intelligence [1].

\footnotetext{
* Corresponding author at: Department of Medicine and Nursing, Federal University of Viçosa, Avenida PH Rolfs s/n, Campus Universitário, CEP 36571-000, Viçosa, MG, Brazil. Tel./fax: +55 3138993906.

E-mail address: fernandomvdias@hotmail.com (F.M.V. Dias).
}

Flyn (2009) states that intelligence is quantified by the I.Q test [2]. Damage or delay in CNS development can cause social adaptation difficulties and deficits in adaptive behavior [3].

During the last few decades, an interesting phenomenon about I.Q has been observed. An important increase in the average of I.Q scoring in populational studies took place in the last decades, in other words, an increase in intelligence, at least, in the more formal sense [4]. However, such an increase cannot be observed in an equivalent way all over the world [5,6]. For instance, underprivileged regions, where the access to healthcare and education is precarious, show a greater risk of having children affected by mental retardation or failing to reach a normal potential in cognitive development [7]. Thus, children who belong to such communities 
later in life have less chance to transform and improve themselves and the social conditions of their communities which generates the perpetuation of poverty in these countries $[8,9]$. Therefore, the factors involved in CNS development should be known, not only as a matter of population health but also as an important aspect related to social improvement [10].

CNS development is influenced by psychosocial and biological factors and by genetic inheritance [8]. These factors together interfere, increasing or decreasing, with cerebral development through neurogenesis, axonal and dendritic growth, synaptogenesis, cell death, synaptic pruning, myelination, and gliogenesis [11]. Among biological factors, malnutrition throughout pregnancy and during early life is clearly identifiable as a cause of damage in CNS development. Although all the nutrients are necessary for proper cerebral development, there is strong evidence that just the deficiency of some micronutrients is enough to influence children's cognition and behavior [12].

Micronutrients such as: iron, iodine, folic acid, vitamin B12 and choline play an important and known role in the process of growth and maturity of CNS. The lack of such micronutrients during pregnancy and breastfeeding may result in mental retardation [13-17].

Although there are some studies focusing the role of thiamine in the brain, the function of this vitamin in the cerebral development process is still not very well known [18]. In addition, the prevalence of thiamine shortcoming may affect as much as $50 \%$ of pregnant women. Despite such high prevalence, there is a gap in the literature of systematic studies about thiamine levels in biological samples of pregnant women in the various periods of gestation and throughout breastfeeding. The lack of scientific data is greater among populations with a high level of nutritional vulnerability. In addition, these populations do not have easy access to proper laboratorial methods. Furthermore, it is very complicated to evaluate the consequences for the children who grew up during the maternal shortcoming.

We hypothesize that thiamine plays an essential role in CNS development and that the maternal deficit throughout pregnancy and breastfeeding could be an important cause of damage to cognitive development among children, mainly in underdeveloped countries across the world.

\section{Thiamine's role in the central nervous system}

Thiamine (B1 vitamin) is an essential nutrient found in a high amount in muscles, organs and cerebral tissue. After being captured by the cells, thiamine can be the rising phosphorylated thiamine pyrophosphate (TDP). Among the thiamine phosphate derivatives, TDP has best known biological function. It acts as a cofactor of the transketolase enzymes, pyruvate dehydrogenase complex and ketoglutarate dehydrogenase, the key enzymes in the cellular energy production process $[20,21]$. The enzymes which depend on thiamine are not only important to maintain the energetic metabolism of the cell, but also act indirectly in the lipid, nucleotide synthesis [21].

In the central nervous system, besides the well described metabolic function of thiamine, as mentioned above, as a cofactor of enzymes which are involved in the glucose metabolism several pieces of work have suggested other non-metabolic functions for thiamine and its derivatives $[18,22,23]$. Other functions described are: neurotransmitter synthesis, plasma membrane structure and function stabilization, participation in the sign transduction pathways and proceedings against cytotoxicity inductor agents [24-27]. Moreover, the results obtained by our group [28], using neuronal primary culture, indicate involvement of thiamine in the ionic channel modulation. The increased content of such a vitamin during synaptogenesis also provides support for its role in the nervous conduction [29].
According to Martin et al. (2003) [30], given the importance of thiamine in the organism, a decrease in its tissue concentration may interfere in several cellular mechanisms, capable of triggering neurodegenerative processes resulting in cerebral functional alterations. These disturbances may result in Wernicke Encephalopathy, in which the main symptoms are ophthalmoplegia, ataxia, memory loss, mental confusion and gait and posture hypoactivity $[31,32]$. Thiamine deficiency is also suggested to be related with autism and delayed language impairment $[33,34]$.

Brain injuries similar to those that occur in individuals with Wernicke Encephalopathy can be induced experimentally in rats through the use of diet lacking thiamine, parenteral use of a pirofosfoquinase inhibitor or a combination of both procedures [35]. In these experimental models, thiamine shortcoming leads to cell loss in the cerebellum, amygdala, thalamus, inferior colliculus andsuperior olivary complex [36,37].

Thus, based on data obtained from experimental and clinical studies, we conclude that thiamine shortcoming severely disrupts neuronal function and results in behavioral changes.

\section{Populations under the risk of thiamine shortcoming}

Thiamine shortcoming affects specific population groups due to an increase of nutritional needs or to the lack of the nutrient intake in malnutrition cases $[31,19]$. There is a connection among socially vulnerable groups, in other words, underprivileged people who face extreme poverty that may be affected by such deficit. Thus, prisoners, refugees and population living under extremely poor conditions are more likely to develop the shortcoming. [38,39].

McGready et al. (2001) observed that women who belonged to a refugee camp on the Thailand-Burma border presented a high level of thiamine deficiency during post partum [40]. More than $58 \%$ of the women in this group presented the deficit in the third month post partum and many of those had subclinical manifestation. In this population infantile beriberi, or thiamine deficiency, was recognized as a major cause of infant mortality. Other studies indicate a high prevalence of thiamine deficiency in other populations, showing that a deeper investigation about maternal shortcoming, as well as its consequences for the offspring are needed $[29,19]$.

Maternal thiamine shortcoming during pregnancy remains until breastfeeding and harms the milk formation [40]. It is widely accepted that the rapid rate of growth of the brain during the last third of gestation and the early postnatal stage makes it more vulnerable to an inadequate diet [41]. That is more evidence that, underprivileged people show a greater risk to present the shortcoming during breastfeeding [42], emphasizing that it can be very harmful to the child.

It can be concluded that poverty, due to the possibility of malnutrition, is an important risk factor to the occurrence of thiamine shortcoming. Likewise, the relation between damage to cognitive development and poverty is well outlined [43]. Clearly, we can conclude that there might be a connection between poverty and thiamine shortcoming, and as a consequence, one could also deduce that thiamine deficiency is related to cognitive developing impairment.

Several psychosocial and biological factors apart from thiamine deficiency contribute directly to cognitive, sensory-motor and social-emotional functions $[44,45]$. There is a methodological difficulty in the research about damage to cognitive development regarding the importance and participation of each one of the factors involved in these functions. Besides, there is a lack of systematic studies which evaluate the mothers in the several periods of gestation and breastfeeding. Futhermore, the consequences for the children's development are unknown, which hinder the estab- 
lishment of a connection between damage to cognitive development and thiamine shortcoming.

\section{Thiamine shortcoming and damage to cognitive development}

Although there is no clear scientific evidence that maternal thiamine shortcoming is directly related to damage to cognitive development during gestation and breastfeeding in humans, we could find evidence of such a relation in two approaches.

Firstly, as already stated above, thiamine plays a fundamental role in the neuronal physiology, from the growth and development process until aging [46]. Therefore, CNS development in an environment that lacks thiamine will probably be negatively affected $[47,33]$. Although cerebral plasticity enables the compensation of the vitamin shortcoming, the molecular mechanism and its limit of action are still unknown.

Secondly, in a translational scientific perspective, we could take advantage of data obtained from other animal models, for instance rodents, to identify the consequences of a thiamine shortcoming during gestation and breastfeeding. Using these animal models the researchers can control the variables not possible to be controlled in human beings. For instance, other fundamental nutritional factors, apart from thiamine, can be controlled avoiding misinterpretation about the consequence of thiamine deficiency. Furthermore, the use of rodent models allows one to know the relationship between thiamine levels in the blood and in the brain.

Fournier \& Butterworth found that thiamine shortcoming during pregnancy leads to neurochemical alterations in the offspring [48]. The cerebral enzyme activities which participate in the energetic metabolism, like transketolase, pyruvate and cetoglutarate dehydrogenase complex, underwent a significant decrease in puppies from deficient mothers when compared to the puppies of control mothers.

Histological studies performed in the hippocampus of rats subjected to maternal shortcoming of thiamine corroborate the importance of such a vitamin for brain development, because its deficiency causes tissue damage that remains in later life $[49,50]$. The morphometric evaluations indicated significant atrophy and a density decrease of the pyramidal and granule cells in the hippocampus subareas of the animals born from thiamine deficient mothers.

In order to evaluate cognitive functions in the offspring, our group made use of animal models with thiamine deficiency during gestation and breastfeeding. When a total deficient thiamine diet was used throughout gestation, we observed that such a high shortcoming prevented the fetal viability generating stillborns (data unpublished). For this reason, we set up a thiamine deficient model adopting a partially deficient diet of $90 \%$. This partial thiamine shortcoming during pregnancy induced spatial learning dysfunctions in offspring (submitted data).

Besides, it was observed that the period straight after birth is the one with the greatest cerebral vulnerability to maternal deficiency of thiamine [50]. The damage to offspring regarding function acquisition, such as reflexes, abilities and gait are more severe in the post natal period. Our group showed for the first time that the cognitive functions of rats that were breastfed by thiamine deficient mothers were impaired [51]. We observed that the shortcoming during breastfeeding causes spatial learning and cerebral GABAergic and glutamatergic dysfunctions in offspring, indicating that this period, crucial to CNS development, is susceptible to the effect of thiamine deficiency. Moreover, in a recent paper, Bâ confirmed the damage to the CNS development with significant behavioral changes in the offspring and indicated that deficiency of thiamine interferes with cellular proliferation and migration, differentiation, synaptogenesis, axogeneseis and myelinogenisis [52].

\section{Conclusion}

Several data indicate thiamine as a fundamental micronutrient to ripeness and growth of the CNS. Thus, the hypothesis that thiamine shortcoming can be a relevant cause of damage to the cognitive development of children throughout the world needs to be strongly considered. Underprivileged regions, where the access to healthcare and education is precarious, show a greater risk of having children affected by mental retardation or failing to reach a normal potential in cognitive development. Those children later in life have less chance to transform and improve themselves and the social conditions of their communities, which generates the perpetuation of poverty in these countries. Thus, systematic studies that evaluate thiamine shortcoming during gestation and breastfeeding and its effects on children should be done in many populations, mainly in those with a high level of nutritional vulnerability. Knowledge the magnitude of this problem will provide support for instituting direct actions to overcome it. Quality of life improvement is the perspective sought by such studies for the underprivileged population.

\section{Conflict of interest statement}

None declared.

\section{References}

[1] Grantham-McGregor S, Cheung Y, Cueto S, Glewwwe P, Richter L, Strupp B. Developmental potential in the first 5 years for children in developing countries. Lancet 2007;369:60-70.

[2] Flynn JR. What is intelligence? Beyond the Flynn effect. Enlarged ed. Cambridge, UK: Cambridge University Press; 2009.

[3] McArdle J, Ferrer-Caja E, Hamagami F, Woodcock R. Comparative longitudinal structural analyses of the growth and decline of multiple intellectual abilities over the life span. Dev Psychol 2002:38:115-42.

[4] Jerison $\mathrm{H}$. The evolution of intelligence. In: Sternberg RJ, editor. Handbook of intelligence. New York, NY: Cambridge University Press; 2000. p. 216-44.

[5] Baker-Henningham H, Powell C, Walker S, Grantham-McGregor S. Mothers of undernourished Jamaican children have poorer psychosocial functioning and this is associated with stimulation provided in the home. Eur J Clin Nutr 2003;57:786-92.

[6] Schady N, Paxson C. Cognitive development among young children in Ecuador: the roles of health, wealth and parenting. In: World bank policy research working paper. Washington: World Bank; 2005.

[7] Walker SP, Chang SM, Powell CA, Grantham-McGregor SM. Effects of early childhood psychosocial stimulation and nutritional supplementation on cognition and education in growth-stunted Jamaican children: prospective cohort study. Lancet 2005;366:1804-7.

[8] Wachs TD. Necessary but not sufficient: the respective roles of single and multiple influences on individual development. Washington, DC: American Psychological Association; 2000.

[9] Engle PL, Bentley M, Pelto G. The role of care in nutrition programmes: current research and a research agenda. Proc Nutr Soc 2000;59:25-35.

[10] Engle PL, Black MM, Behrman JR, Mello MC, Gertler PJ, Kapiriri L, et al. Strategies to avoid the loss of developmental potential in more than 200 million children in the developing world. Lancet 2007:369:145-57.

[11] Mandelman SD, Grigorenko EL. Intelligence: genes, environments, and their interactions. In: Sternberg RJ, Kaufman SB, editors. Cambridge handbook of intelligence. New York, NY: Cambridge University Press; 2011. p. 85-106.

[12] Benton D. Micronutrients status, cognition and behavioral problems in childhood. Eur J Nutr 2008;47:38-50.

[13] Zlotkin SH, Christofi des AL, Hyder SM, Schauer CS, Tondeur MC, Sharieff W. Controlling iron deficiency anemia through the use of home-fortified complementary foods. Indian J Pediatr 2004;71:1015-9.

[14] Delange F. Iodine deficiency as a cause of brain damage. Postgrad Med J 2001;77:217-20

[15] Sofer Y, Harel L, Sharkia M, Amir J, Schoenfeld T, Straussberg R. Neurological manifestations of folate transport defect: case report and review of the literature. J Child Neurol 2007;22(6):783-6.

[16] Katar S, Nuri Ozbek M, Yaramis A, Ecer S. Nutritional megaloblastic anemia in young Turkish children is associated with vitamin B-12 deficiency and psychomotor retardation. J Pediatr Hematol Oncol 2006;28(9):559-62.

[17] Zeisel SH. The fetal origins of memory: the role of dietary choline in optimal brain development. J Pediatr 2006;149:S131-6.

[18] Bâ A. Metabolic and structural role of thiamine in nervous tissue. Cell Mol Neurobiol 2008:923-31. 
[19] Baker H, De Angelis B, Holland B, Gittnes-Wiliams L, Barret Jr T. Vitamin profile of 563 pregnant during trimestres of pregnancy. J Am Coll Nutr 2002;21:33-7.

[20] Pannunzio P, Hazell AS, Pannuzio M, Rao KV, Butterworth RF. Thiamine deficiency results in metabolic acidosis and energy failure in cerebellar granule cells: an in vitro model for the study of cell death mechanisms in Wernicke's encephalopathy. J Neurosci Res 2000;62:286-92.

[21] Berg J, Tymoczo J, Stryer L. Biochemistry. 5rd ed. New York: W.H. Freeman and Company; 2004.

[22] Mulholland P. Susceptibility of the cerebellum to thiamine deficiency. Cerebellum 2006;5:55-63.

[23] Navarro D, Zwingmann C, Butterworth R. Impaired oxidation of branchedchain amino acids in the medial thalamus of thiamine-deficient rats. Metab Brain Dis 2008;23:445-55.

[24] Goldberg DJ, Begenisich TB, Cooper JR. Effects of thiamine antagonists on nerve conduction. II. Voltage clamp experiments with antimetabolites. J Neurobiol 2004;6:453-62.

[25] Czerniecki J, Chanas G, Verlaet M, Bettendorff L, Makarchikov AF, Leprince P, et al. Neuronal localization of the 25- rodent brain. Neuroscience 2004; $125: 833-40$.

[26] Bâ A, Seri B, Han S. Thiamine administration during chronic alcohol intake in pregnant and lactating rats: effects on the offspring neurobehavioral development. Alcohol 1996;31:27-40.

[27] Aberle N, Burd L, Zhao BH, Ren J. Acetaldehyde-induced cardiac contractile dysfunction may be alleviated by vitamin B1 but not vitamins B6 or B12. Alcohol 2004;39:450-4.

[28] Oliveira FA, Galan DT, Ribeiro AM, Santos Cruz J. Thiamine deficiency during pregnancy leads to cerebellar neuronal death in rat offspring: role of voltage dependent K+ channels. Brain Res 2007;1134(1):79-86.

[29] Ramakrishnan U, Manjrekar R, River J, Gonzales-Cossio T, Martorell R. Micronutrients and pregnancy outcome: a review of the literature. Nutr Res 1999;19:103-59.

[30] Martin PR, Singleton CK, Hiller-Sturmhöfel S. The role of thiamine deficiency in alcoholic brain disease. Alcohol Res Health 2003;27:134-42.

[31] Butterworth R. Thiamin deficiency and brain disorders. Nutr Res Rev 2003;16:277-83.

[32] Zubaran C, Fernandes JG, Rodnight R. Wernicke-Korsakoff syndrome. Postgrad Med J 1997;73:27-31.

[33] Fattal-Valevski A, Azouri-Fattal I, Greenstein YJ, Guindy M, Blau A, Zelnik N. Delayed language development due to infantile thiamine deficiency. Dev Med Child Neurol 2009;51(8):629-34.

[34] Shamberger RJ. Autism rates associated with nutrition and the WIC program. J Am Coll Nutr 2011;30(5):348-53.

[35] Langlais PJ, Zhang SX, Savage LM. Neuropathology of thiamine deficiency: an update on the comparative analysis of human disorders and experimental models. Metab Brain Dis 1996;11:19-37.

[36] Irle E, Markowitsch HJ. Widespread neuroanatomical damage and learning deficits following chronic alcohol consumption or vitamin B1 (thiamine) deficiency in rats. Behav Brain Res 1983;9:277-94.
[37] Vortmeyer AO, Colmant HJ. Differentiation between brain lesions in experimental thiamine deficiency. Virchows Arch A Pathol Anat Histopathol 1988;414:61-7.

[38] Basoglu M, Yetimalar Y, Gurgor N, et al. Neurological complications of prolonged hunger strike. Eur J Neurol 2006;13:1089-97.

[39] Adamolekun B. Etiology of Konzo, epidemic spastic paraparesis associated with cyanogenic glycosides in cassava: role of thiamine deficiency? J Neurol Sci 2010:30-3.

[40] McGready R, Simpson JA, Cho T, et al. Postpartum thiamine deficiency in a Karen displaced population. Am J Clin Nutr 2001;74:808-13.

[41] Drewett R, Wolked D, Asefa M, Kaba M, Tessera F. Malnutrition and mental development: is there a sensitive period? A nested case-control study. J Child Psychol Psychiat 2000;42:181-7.

[42] Stuetz W, Carrara VI, McGready R, Lee SJ, Erhardt JG, Breuer J, et al. Micronutrient status in lactating mothers before and after introduction of fortified flour: cross-sectional surveys in Maela refugee camp. Eur J Nutr 2011 [Epub ahead of print].

[43] Walker SP, Wachs TD, Meeks Gardner J, et al. The International Child Development Steering Group. Child development: risk factors for adverse outcomes in developing countries. Lancet 2007;369:145-57.

[44] Masten A, Powell J. A resilience framework for research, policy, and practice. In: Luthar S, editor. Resilience and vulnerability: adaptation in the context of childhood adversities. New York: Cambridge University Press; 2003. p. 1-28.

[45] Li H, DiGirolamo AM, Barnhart HX, Stein AD, Martorell R. Relative importance of birth size and postnatal growth for women's educational achievement. Early Hum Dev 2004;76:1-16.

[46] Zhang Q, Yang G, Li W, Fan Z, Sun A, Luo J, et al. Thiamine deficiency increases $\beta$-secretase activity and accumulation of $\beta$-amyloid peptides. Neurobiol Aging 2011;32(1):42-53.

[47] McGready R, Simpson JA, Arunjerdja R, Golfetto I, Ghebremeskel K, Taylor A et al. Delayed visual maturation in Karen refugee infants. Ann Trop Paediatr 2003;23(3):193-204.

[48] Fournier H, Butterworth RF. Effects of thiamine deficiency on thiaminedependent enzymes in regions of the brain of pregnant rats and their offspring. Metab Brain Dis 1990;5(2):77-84.

[49] Bâ A, Seri BV, Aka KJ, Glin L, Tako A. Comparative effects of developmenta thiamine deficiencies and ethanol exposure on the morphometry of the CA3 pyramidal cells. Neurotoxicol Teratol 1999;21:579-86.

[50] Bâ A. Functional vulnerability of developing central nervous system to maternal thiamine deficiencies in the rat. Dev Psychobiol 2005;47:408-14.

[51] Freitas-Silva DM, Resende LS, Pereira SRC, Franco GC, Ribeiro AM. Maternal thiamine restriction during lactation induces cognitive impairments and changes in glutamate and GABA concentrations in brain of rat offspring. Behav Brain Res 2010:33-40.

[52] Bâ A. Comparative effects of alcohol and thiamine deficiency on the developing central nervous system. Behav Brain Res 2011;225(1):235-42. 